\title{
HER-2 and HER-3 expression in liver metastases of patients with colorectal cancer
}

\author{
Hanna Styczen ${ }^{1}$, Iris Nagelmeier ${ }^{2}$, Tim Beissbarth ${ }^{3}$, Manuel Nietert ${ }^{3}$, Kia \\ Homayounfar $^{1}$, Thilo Sprenger ${ }^{1}$, Ute Boczek ${ }^{1}$, Kathrin Stanek ${ }^{1}$, Julia Kitz ${ }^{4}$, Hendrik \\ A. Wolff ${ }^{5}$, B. Michael Ghadimi ${ }^{1}$, Peter Middel ${ }^{2}$, Torsten Liersch ${ }^{1}$, Josef Rüschoff ${ }^{2}$, \\ Lena-Christin Conradi ${ }^{1}$ \\ ${ }^{1}$ Department of General, Visceral and Pediatric Surgery, University Medical Center, Göttingen, Germany \\ ${ }^{2}$ Targos Molecular Pathology, Pathology Nordhessen, Kassel, Germany \\ ${ }^{3}$ Department of Medical Statistics, University Medical Center, Göttingen, Germany \\ ${ }^{4}$ Department of Pathology, University Medical Center, Göttingen, Germany \\ ${ }^{5}$ Department of Radiotherapy and Radiooncology, University Medical Center, Göttingen, Germany \\ Correspondence to: \\ Lena-Christin Conradi, e-mail: lena.conradi@med.uni-goettingen.de \\ Keywords: colorectal cancer, HER-2, HER-3, targeted therapy, liver metastases \\ Received: January 25, $2015 \quad$ Accepted: March 09, $2015 \quad$ Published: April 13, 2015
}

\section{ABSTRACT}

Objective: In this study, we evaluate the frequency of HER-2 and HER-3 expression in liver metastases from patients with colorectal cancer (CRLM). We analyzed the potential of HER-2 and HER-3 as therapeutic targets and evaluated their prognostic value.

Patients and Methods: Overall 208 patients with CRLM were enrolled. HER-2 and HER-3 expression were determined in metastatic tissue of diagnostic punch biopsies $(n=29)$ or resection specimens $(n=179)$. The results of immunohistochemistry (IHC) scoring and In-situ-hybridization (ISH)-amplification were correlated with clinical parameters and for the 179 resected patients with cancer-specific (CSS) and overall survival (OS). The mean follow-up time was $\mathbf{5 6 . 7}$ months.

Results: Positivity of HER-2 status (IHC score $2+/$ ISH+ and IHC $3+$ ) was found in 8.2\% of CRLM. High expression of HER-3 (IHC score $2+$ and IHC $3+$ ) was detected in $\mathbf{7 5 . 0} \%$ of liver metastases. CSS after liver surgery was determined and was independent from the HER-2 status $(p=0.963)$; however HER-3 was prognostic with a favorable course for patients showing an overexpression of HER-3 $(p=0.037)$.

Conclusions: HER-2 overexpression occurs in only $8 \%$ of patients with CRLM but with $75 \%$ of cases HER-3 is frequently overexpressed in CRLM. Therefore, HER-2 and particularly HER-3 could serve as novel targets to be addressed within multimodal treatment approaches.

\section{INTRODUCTION}

Colorectal cancer (CRC) is the third most common cancer in the United States and also the third leading cause of cancer related deaths [1]. High incidence rates of CRC are reported mainly in developed countries with a Western culture including the United States, Australia, New Zealand, Canada and Western Europe [2][3][4]. The implementation of multimodal therapy including preoperative chemo- radiotherapy (CRT) has led to an reduction of local recurrences, the introduction of total mesorectal excision (TME) followed by adjuvant chemotherapy with 5-FU and oxaliplatin [5] and complete mesocolic excision (CME) as well as the availability of new biological substances in the last two decades are aiming to improve prognosis of patients with (metastatic) CRC [6][7][8].

However, the occurrence of distant metastases limits the prognosis of these patients. Rates up to $30-50 \%$ of metastases during the course of malignancy are 
reported with a predominant location in the liver followed by the lung. Besides Radiofrequency ablation (RFA) and stereotactic body radiation therapy (SBRT) histopathologically confirmed $\mathrm{R} 0$ resection in potentially curative intent is a favorable option in case of technical resectability. Due to technical progress in liver surgery and access to innovative treatment approaches, the prognosis of patients with colorectal liver metastases has dramatically improved [9]. Data on survival vary, but about $17-32 \%$ of patients qualify for surgical resection of liver metastases [10][11], leading to 5-year overall survival (OS) rates ranging from $32-33 \%$ [11][12] to up to $58 \%$ [13] and 10-year OS rates of about $18 \%$ [11].

For those patients, whose metastases remain surgically unresectable and who are treated with chemotherapy (CTx) alone, median survival rates are currently reported with 13.9 - 17.4 months [14][15]. In the last decades, metastatic CRC has been treated with Fluoropyrimidine-based CTx and recently in the combination with irinotecan or oxaliplatin. Due to nonspecificity of this treatment, there have been major initiatives in targeted therapy of CRC using antibody based products such as cetuximab. In several studies including recent data from the CELIM trial, it has been demonstrated that initially unresectable colorectal liver metastases can be resected after response to cetuximab based CTx leading to a better overall survival of these patients [16][17]. Patients who respond to conversion therapy and undergo secondary surgery achieve a better median OS of 53.9 months compared to those who do not (21.9 months; $p<0.001$ ) [16]. Still, the evaluation of new agents targeting molecular pathways that are expressed strongly by tumor cells is crucial to develop innovative treatment approaches.

In this context we evaluated the transmembrane receptor HER-2, a family member of the epidermal growth factor receptor family (EGFR). HER-2 is already known as a prognostic biomarker in various solid tumors (for more than a decade in breast cancer [18][19], more recently for gastric cancer [20], esophageal adenocarcinoma [21], pancreatic [22] and rectal cancer [23]) and even more importantly as a potential target in the specific tumor therapy in clinical routine for breast and metastatic gastric cancer. Data on the prognostic value of HER-2 in GI-malignancies still remains less clear. The ToGA-trial showed a HER-2 positivity of $22.1 \%$ [20][24] in gastric cancer and adenocarcinoma of the gastro-esophageal junction (overall $n=584$ HER-2 positive) using a specific modified immunohistochemistry (IHC) scoring algorithm in comparison to breast cancer [20][25]. Patients with overexpression of HER-2 (IHC 3+, IHC 2+/FISH+) had a better survival compared to patients with no or weak HER-2 expression levels (IHC 0, IHC 1+, IHC 2+/FISH-). These patients treated with trastuzumab additionally to standard CTx benefited significantly from the individualized therapy [20]. Comparable studies using the same IHC scoring criteria showed a HER-2 positivity of $17 \%$ in adenocarcinomas of the esophagus and of $27 \%$ in resection specimens of patients with cUICC-II/-III rectal cancer [21] [23]. Both studies demonstrated the correlation of a high HER-2 expression with better survival in gastrointestinal cancer. On the contrary, in breast cancer HER-2 positivity seems to be associated with a higher occurrence of brain metastases and reduced survival.

In several published meta-analyses it has been shown that HER-2 overexpression was correlated with decreased survival in CRC patients suggesting that HER-2 overexpression might not be a prognostic indicator [26] [27]. In metastatic CRC, Aprile et al. [28] reported a negative prognostic value of HER-2 expression in brain metastases.

In this study we evaluate the frequency of HER-2 positivity in CRLM and in a very small subgroup of patients also in corresponding primary tumor resection specimens. Furthermore we analyzed if HER-2 could be a prognostic biomarker or could, when being overexpressed, in the future serve as a therapeutic target. In addition, we assessed the expression of the EGFR family member HER-3 whose role in metastatic CRC has not been fully analyzed and is not understood yet. A recent publication showed a HER-3 expression in about $70 \%$ of primary tumors of stage II and III CRC and in about $75 \%$ of corresponding lymph node metastases [29]. High expression of HER-3 was even assessed with worse clinical outcome. So HER-3 could remain as an independent (from post-resection therapy) prognostic factor for distant metastases [29][30] and could even be targeted specifically by a therapeutic antibody [31].

\section{RESULTS}

\section{HER-2 status in liver metastases and corresponding primary tumors}

Positive HER-2 status (IHC 2+/ISH+ and IHC 3+) was detected in $8.2 \%(17 / 208)$ of CRLM and in $18.2 \%$ $(4 / 22)$ of the very small subgroup of patients with a resection specimens in primary tumors (Table 3$)$. DualISH was performed in 46 specimens (33 metastases and 13 primary tumors) classified IHC $2+$, to determine gene amplification. About $75 \%$ of tissue specimens revealed heterogeneous or focal expression ( $\leq 30 \%$ of HER-2 positive cancer cells) of HER-2. Positivity of HER-2 status was found in $6 \%$ of synchronous metastases and in $11 \%$ of the metachronous metastases (Table 1). Furthermore, HER-2 was in trend more often overexpressed in metastases of colon cancer $(n=8 ; 12.1 \%)$ compared to metastases of rectal adenocarcinomas $(n=9 ; 6.3 \%)$.

Within the 22 matched paired samples, 4 primary cancer samples and 2 CRLM samples showed HER-2 overexpression but in none of these cases the matched 
Table 1: Demographics and clinical parameters $(N=208)$

\begin{tabular}{|c|c|c|c|c|c|c|c|c|}
\hline \multirow[t]{2}{*}{ Clinical Parameters } & \multicolumn{4}{|c|}{ HER-2 } & \multicolumn{4}{|c|}{ HER-3 } \\
\hline & $N=\mathbf{2 0 8}$ & $\%$ & $\begin{array}{c}\text { Low } \\
\text { expression }\end{array}$ & $\begin{array}{c}\text { High } \\
\text { expression }\end{array}$ & $p$-value & $\begin{array}{c}\text { Low } \\
\text { expression }\end{array}$ & $\begin{array}{c}\text { High } \\
\text { expression }\end{array}$ & $p$-value \\
\hline Age, median and range & \multicolumn{8}{|c|}{67.5 years $(40-90$ years $)$} \\
\hline $\begin{array}{l}\text { Gender } \\
\text { Female } \\
\text { Male }\end{array}$ & $\begin{array}{c}71 \\
137\end{array}$ & $\begin{array}{l}34 \\
66\end{array}$ & $\begin{array}{c}65(91.5 \%) \\
126(91.9 \%)\end{array}$ & $\begin{array}{c}6(8.5 \% \\
11(8.0 \%)\end{array}$ & NS & $\begin{array}{l}12(16.9 \%) \\
40(29.2 \%)\end{array}$ & $\begin{array}{l}59(83.1 \%) \\
97(70.8 \%)\end{array}$ & NS \\
\hline $\begin{array}{l}\text { Distant metastases } \\
\text { Hepatic } \\
\text { Further distant organ } \\
\text { metastases }\end{array}$ & $\begin{array}{l}117 \\
91\end{array}$ & $\begin{array}{l}56 \\
44\end{array}$ & $\begin{array}{l}109(93.2 \%) \\
82(90.1 \%)\end{array}$ & $\begin{array}{l}8(6.8 \%) \\
9(9.9 \%)\end{array}$ & NS & $\begin{array}{l}28(23.9 \%) \\
24(26.4 \%)\end{array}$ & $\begin{array}{l}89(76.1 \%) \\
67(73.6 \%)\end{array}$ & NS \\
\hline $\begin{array}{l}\text { Hepatic metastases } \\
\text { One lobe of the liver } \\
\text { Two lobes } \\
\text { Diffuse metastases }\end{array}$ & $\begin{array}{c}105 \\
89 \\
14 \\
\end{array}$ & $\begin{array}{c}50 \\
43 \\
7 \\
\end{array}$ & $\begin{array}{l}96(91.4 \%) \\
82(92.1 \%) \\
13(92.9 \%) \\
\end{array}$ & $\begin{array}{l}9(8.6 \%) \\
7(7.9 \%) \\
1(7.1 \%) \\
\end{array}$ & NS & $\begin{array}{c}22(21.0 \%) \\
24(27.0 \%) \\
6(42.9 \%) \\
\end{array}$ & $\begin{array}{c}83(79.0 \%) \\
65(73.0 \%) \\
8(57.1 \%) \\
\end{array}$ & NS \\
\hline $\begin{array}{l}\text { Hepatic metastases } \\
\text { Synchronous } \\
\text { Metachronous }\end{array}$ & $\begin{array}{c}118 \\
90\end{array}$ & $\begin{array}{l}57 \\
43\end{array}$ & $\begin{array}{c}111(94.1 \%) \\
80(88.9 \%)\end{array}$ & $\begin{array}{c}7(5.9 \%) \\
10(11.1 \%)\end{array}$ & NS & $\begin{array}{l}34(28.8 \%) \\
18(20.0 \%)\end{array}$ & $\begin{array}{l}84(71.2 \%) \\
72(80.0 \%)\end{array}$ & NS \\
\hline $\begin{array}{l}\text { Primary tumor } \\
\text { Colon } \\
\text { - right sided } \\
\text { - left sided } \\
\text { Rectum }\end{array}$ & $\begin{array}{c}20 \\
46 \\
142\end{array}$ & $\begin{array}{l}10 \\
22 \\
68\end{array}$ & $\begin{array}{c}16(80.0 \%) \\
42(91.3 \%) \\
133(93.7 \%)\end{array}$ & $\begin{array}{l}4(20.0 \%) \\
4(8.7 \%) \\
9(6.3 \%)\end{array}$ & NS & $\begin{array}{c}5(25.0 \%) \\
9(19.6 \%) \\
38(26.8 \%)\end{array}$ & $\begin{array}{c}15(75.0 \%) \\
37(80.4 \%) \\
104(73.2 \%)\end{array}$ & NS \\
\hline $\begin{array}{l}\text { Resected primary tumor } \\
\text { Not resected primary } \\
\text { tumor }\end{array}$ & $\begin{array}{c}203 \\
5\end{array}$ & $\begin{array}{l}98 \\
2\end{array}$ & $\begin{array}{c}186(91.6 \%) \\
5(100 \%)\end{array}$ & $\begin{array}{c}17(8.4 \%) \\
0\end{array}$ & & $\begin{array}{c}51(25.1 \%) \\
1(20 \%)\end{array}$ & $\begin{array}{c}152(74.9 \%) \\
4(80 \%)\end{array}$ & \\
\hline $\begin{array}{l}\text { UICC-Status at } \\
\text { diagnosis of the primary } \\
\text { I } \\
\text { II } \\
\text { III } \\
\text { IV } \\
\text { NA }\end{array}$ & $\begin{array}{c}5 \\
10 \\
18 \\
118 \\
57\end{array}$ & $\begin{array}{c}2 \\
5 \\
9 \\
57 \\
27\end{array}$ & $\begin{array}{c}5(100 \%) \\
10(100 \%) \\
15(83.3 \%) \\
111(94.1 \%) \\
50(87.7 \%)\end{array}$ & $\begin{array}{c}0 \\
0 \\
3(16.7 \%) \\
7(5.9 \%) \\
7(12.3 \%)\end{array}$ & NS & $\begin{array}{c}3(60 \%) \\
0 \\
5(27.8 \%) \\
34(28.8 \%) \\
10(17.5 \%)\end{array}$ & $\begin{array}{c}2(40 \%) \\
10(100 \%) \\
13(72.2 \%) \\
84(71.2 \%) \\
47(82.5 \%)\end{array}$ & NS \\
\hline
\end{tabular}

Basic clinical data are shown according to HER-2 and HER-3 status of hepatic metastases (low HER-2 expression = IHC 0, IHC 1+, IHC 2+/ISH negative, high HER-2 expression = IHC 3+, IHC 2+/ISH positive; low HER-3 expression = IHC 0, IHC 1+, high HER-3 expression = IHC 2+, IHC 3+)

tissue samples showed this overexpression in the same way (Table $4 p=0.48$ ).

\section{HER-3 expression in liver metastases and corresponding primary tumors}

Overall, HER-3 expression was assessed for 208 tissue specimens of liver metastases and 22 of primary tumors. We found high expression (IHC $2+$ and IHC $3+$ ) in $75.0 \%$ samples $(n=156)$ of CRLM and in $72.7 \%$ of the primary tumors $(n=16)$ (Table 3$)$. Heterogeneity or focal expression of HER-3 was detected in $75 \%$ tissue samples comparable to HER-2 expression analyses. HER-3 expression in metastases did correlate with the HER-3 expression in corresponding primary tumors only in trend $(p=0.06)$. About $64 \%(n=14)$ had high HER-3 expression in both tissue samples, the primary and the metastases (Table 4).

Similar to the results of HER-2 expression analysis, HER-3 was found in a greater extend in metachronous metastases $(n=72 ; 80 \%)$ and in metastases of colon cancer $(n=52 ; 78.8 \%)$.

\section{Correlation of HER-2 and HER-3 expression with clinical parameters and outcome}

HER-2 and HER-3 expression analyses were correlated with clinico-pathological parameters (such as gender, primary tumor localization, UICC status at 
Table 2: Long-term follow up of patients

Follow Up

HER-2

HER-3

Last update 12/2013

$\begin{array}{ccccccc}N=208 & \% & \begin{array}{c}\text { Low } \\ \text { Expression }\end{array} & \begin{array}{c}\text { High } \\ \text { expression }\end{array} & p \text {-value } & \begin{array}{c}\text { Low } \\ \text { expression }\end{array} & \begin{array}{c}\text { High } \\ \text { expression }\end{array}\end{array}$

\begin{tabular}{|l|c|c|c|c|c|c|c|c|}
\hline Mean and Range & \multicolumn{8}{|c|}{56.7 months $(0.6-277.8$ months) } \\
\hline Cancer related death & 134 & 64 & $125(93.3 \%)$ & $9(6.7 \%)$ & & $36(26.9 \%)$ & $98(73.1 \%)$ & \\
\hline No cancer related death & 14 & 7 & $14(100 \%)$ & 0 & NS & $3(21.4 \%)$ & $11(78.6 \%)$ & NS \\
\hline Still alive & 60 & 29 & $52(86.7 \%)$ & $8(13.3 \%)$ & & $13(21.7 \%)$ & $47(78.3 \%)$ & \\
\hline
\end{tabular}

Table 3: HER-2 expression in metastases and primary tumors assessed with IHC and Dual-ISH and HER-3 expression as assessed by IHC

\begin{tabular}{|c|c|c|c|c|c|}
\hline IHC/ISH score for HER-2 expression & $\mathbf{0}$ & $1+$ & 2- (ISH-) & $2+(\mathrm{ISH}+)$ & $3+$ \\
\hline $\begin{array}{l}\text { HER-2 expression and gene amplification in } \\
\text { metastases }(n=208)\end{array}$ & $133(63.9 \%)$ & $33(15.9 \%)$ & $25(12.0 \%)$ & $8(3.8 \%)$ & $9(4.3 \%)$ \\
\hline $\begin{array}{l}\text { HER-2 expression and gene amplification in } \\
\text { primary tumors }(n=22)\end{array}$ & $3(13.6 \%)$ & $5(22.7 \%)$ & $10(45.5 \%)$ & $3(13.6 \%)$ & $1(4.5 \%)$ \\
\hline IHC score for HER-3 expression & $\mathbf{0}$ & $1+$ & \multicolumn{2}{|c|}{$2+$} & $3+$ \\
\hline HER-3 expression in metastases $(n=208)$ & $51(24.5 \%)$ & $1(0.5 \%)$ & \multicolumn{2}{|c|}{$63(30.3 \%)$} & $93(44.7 \%)$ \\
\hline HER-3 expression in primary tumors $(n=22)$ & $5(22.7 \%)$ & $1(4.5 \%)$ & \multicolumn{2}{|c|}{$2(9.1 \%)$} & $14(63.6 \%)$ \\
\hline
\end{tabular}

Table 4: HER-2 and HER-3 status in the subgroup of metastases and corresponding primary colorectal tumors $(n=22$; HER-2: $p=0.48$, HER-3: $p=0.06)$

Metastases

$\begin{array}{cc}\text { HER-2 negative } & \text { HER-2 positive } \\ (0 / 1+/ 2-\text {; ISH- }) & (2+\text {; ISH+/3+) }\end{array}$

HER-2 negative
$(0 / 1+/ 2$-; ISH-)

$(2+; \mathrm{ISH}+/ 3+)$

\begin{abstract}
HER-3 low
expression
\end{abstract}

(IHC score 0/1)
HER-3 high

expression

(IHC score 2/3)

\begin{tabular}{|l|c|c|c|c|}
\hline \multicolumn{5}{|l|}{ Primary tumors } \\
\hline HER-2 negative (0/1+/2-; ISH-) & $16(73 \%)$ & $2(9 \%)$ & - & - \\
\hline HER-2 positive (2+; ISH+/3+) & $4(18 \%)$ & $0(0 \%)$ & - & - \\
\hline $\begin{array}{l}\text { HER-3 low expression (IHC } \\
\text { score 0/1) }\end{array}$ & - & - & $3(14 \%)$ & $3(14 \%)$ \\
\hline $\begin{array}{l}\text { HER-3 high expression (IHC } \\
\text { score 2/3) }\end{array}$ & - & - & $2(9 \%)$ & $14(64 \%)$ \\
\hline
\end{tabular}

diagnosis), OS and CSS and were tested for statistical significance. These results are presented in Table 1 and Table 2. We did not find any correlation between high expression of HER-2 or HER-3 and clinico-pathological parameters. With a mean follow up time of 56.7 months, patients with high HER-3 expression showed a better CSS $(p=0.037)$ and a better OS $(p=0.049)$ (Figure 3$)$. The 5-year CSS of patients with high HER-3 expression was 43.5\%, whereas patients with low HER-3 expression had a 5 -year CSS of $23.9 \%$. The 10 -year survival (CSS) was $26.1 \%$ (high HER-3 expression) versus $15.9 \%$ (low HER-
3 expression). Analyses of the prognostic significance of HER-2 expression revealed no difference in CSS ( $p=$ $0.963)$ or OS ( $p=0.747)$ (Figure 4).

\section{DISCUSSION}

HER-2 and HER-3 are members of the EGFR superfamily and involved in central molecular pathways (PI3K/AKT and MAPK) in pathogenesis of solid tumors [32]. HER-2 dimerizes preferentially with the HER-3 receptor initiating potential signal transduction leading 

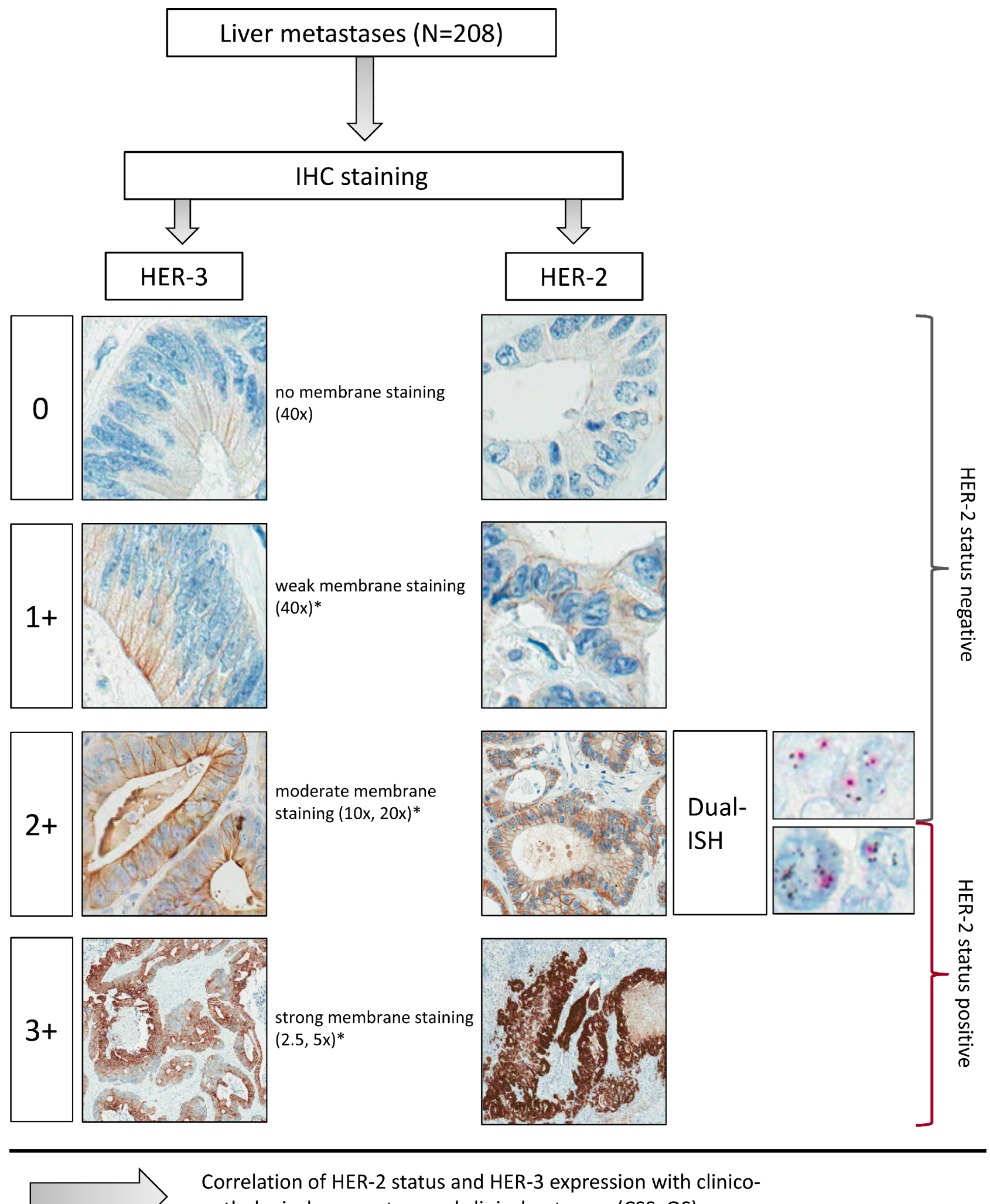
pathological parameters and clinical outcome (CSS, OS)

Figure 1: Examples of HER-2 and HER-3 immunohistochemical staining and Dual-ISH according to the HER-2 algorithm. This figure shows the HER-2 algorithm with examples of HER-2 and HER-3 according to the magnification rule as adopted from gastric cancer scoring for HER-2. $*$ in $\geq 10 \%$ tumor cells in resection specimens. 


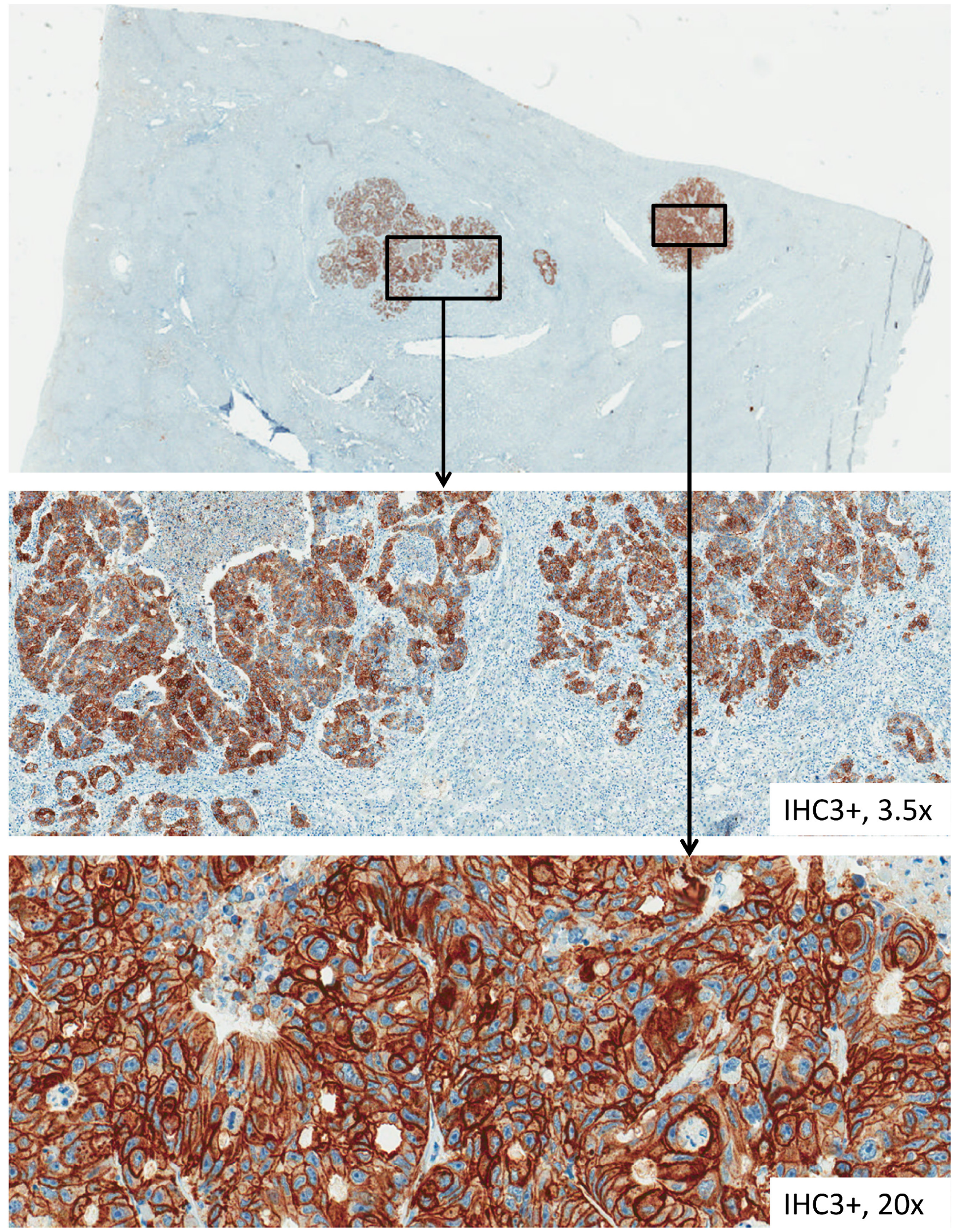

Figure 2: HER-3 immunohistochemical staining of tissue samples from liver metastases. This figure pictures tissue samples from HER-3 immunohistochemical staining from CRC liver metastases with various factors of magnification. 

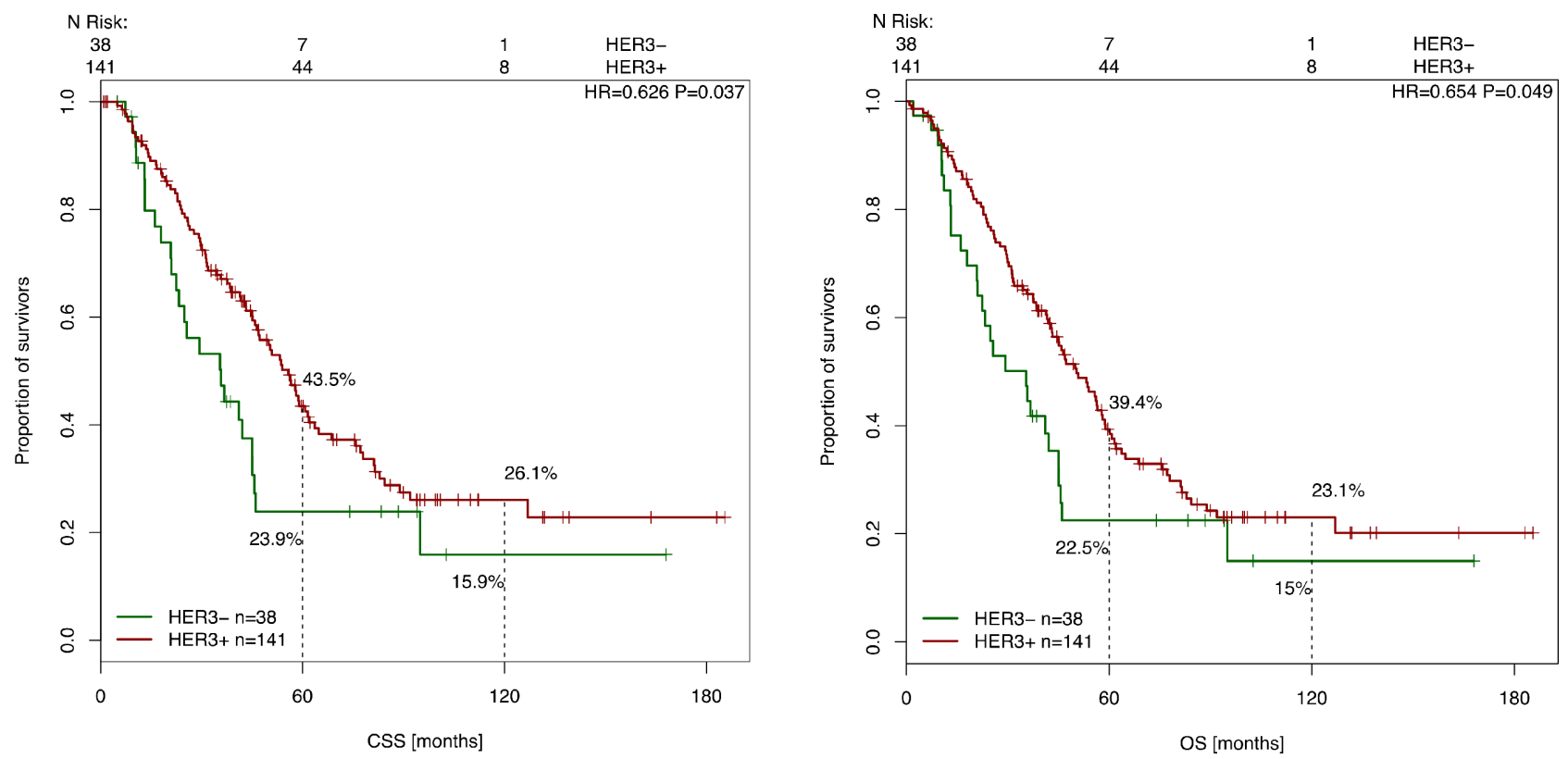

Figure 3: Cancer-specific and overall survival after liver surgery in correlation with HER-3 expression. Kaplan-Meier curve for CSS and OS of CRC patients with high and low HER-3 expression levels $(p=0.037, p=0.049)$. The Cox model for CSS and OS based on HER-3 status from 179 resection specimens of liver metastases.
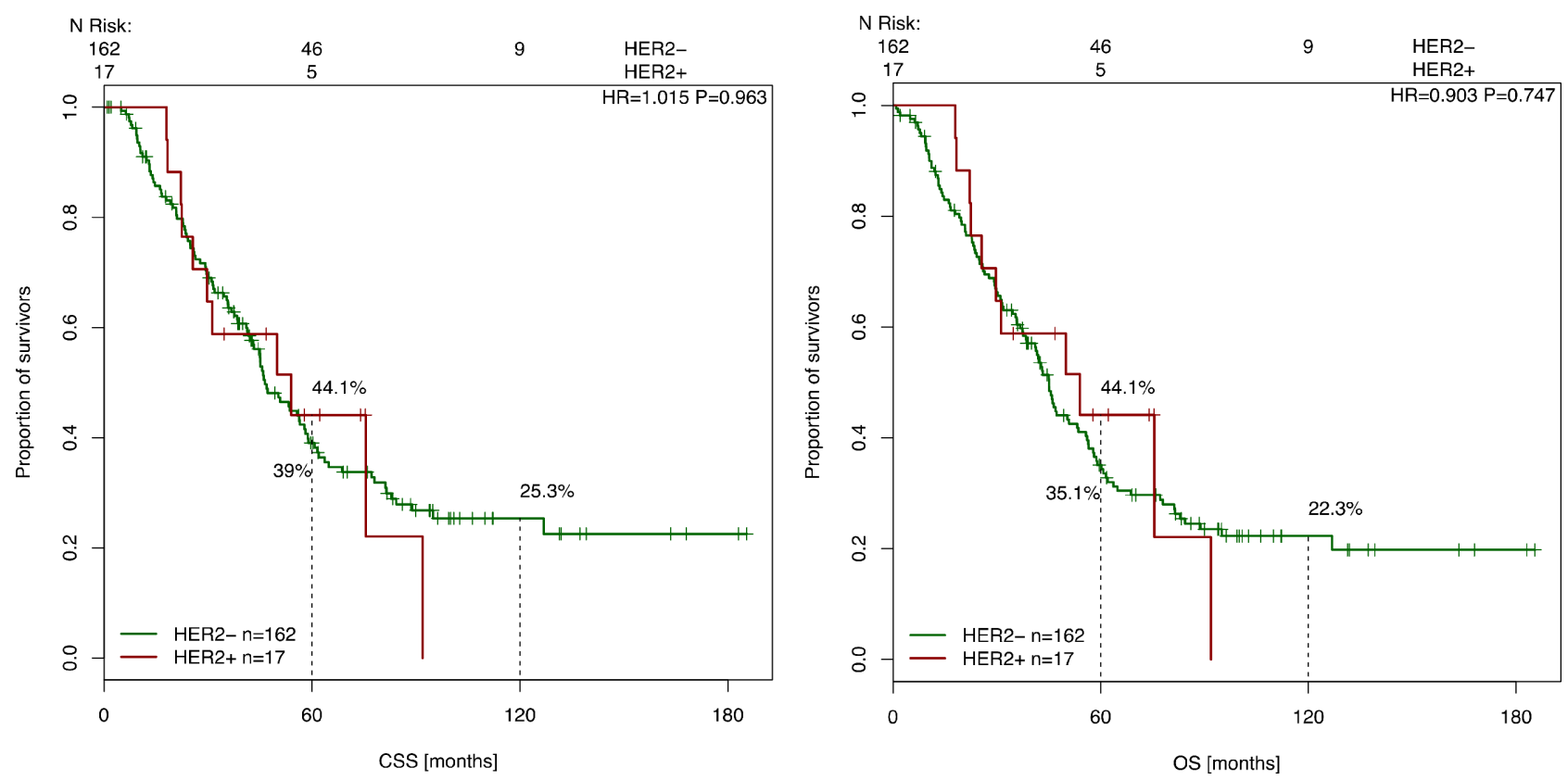

Figure 4: Cancer-specific and overall survival survival after liver surgery in correlation with HER-2 expression. KaplanMeier curve for CSS and OS of CRC patients with high and low HER-2 expression levels ( $p=0.963, p=0.747)$. The Cox model for CSS based on HER-2 status from 179 resection specimens of liver metastases.

to cell proliferation, angiogenesis and formation of metastases [33]. Several studies have reported varying expression levels of HER-2 and HER-3 and evaluated their correlation with clinico-pathological parameters and prognosis but with divergent results [23][28][29][34] [35]. Still, in a variety of solid tumors, the HER-2 receptor represents an effective target for monoclonal antibodies such as trastuzumab being approved for metastatic gastric cancer, pertuzumab [36] or antibody-drug-conjugates such as T-DM-1 [37] and for small tyrosine kinase inhibitors like lapatinib [38] and afatinib [39]. Besides, also HER-3 is considered as an important therapeutic 
target. Anti-HER-3 antibodies such as MM-121 (http:// ClinicalTrials.gov: NCT01451632), RG7116 (http:// ClinicalTrials.gov: NCT01482377) and U3-1287 [40] are currently being tested in several clinical trials spanning various patient populations including CRC patients. In metastatic CRC, data about significance of HER-2 and HER-3 overexpression is lacking. Therefore, we aimed to evaluate the expression pattern of HER-2 as well as HER3 in CRLM to explore their possible prognostic values and verify if they could serve as potential targets in patients with metastatic CRC.

In the present analysis, high HER-3 expression was detected in $75 \%$ of CRLM and in $73 \%$ of resection specimens of primary tumors in CRC patients. Even though several studies assessed cytoplasmatic [41][42][43] rather than membranous staining pattern for the HER-3 receptor, we considered membranous immunostaining of the tumor cells only according to manufacturer's instructions. HER-3 stained tissue samples were similar to the HER-2 staining pattern and were characterized by distinct heterogeneity or focal expression ( $75 \%$ of tissue specimens had $\leq 30 \%$ of HER-2/ HER-3 positive cancer cells) as observed in previously published studies in gastrointestinal cancer [20][23]. The frequency of exclusive membrane staining of HER-3 were also reported in studies on primary tumors in CRC patients by Ledel et al. [29] $(n=236)$ and in colon cancer patients by Beji et al. [34] $(n=110)$. Similar to our data, Ledel et al. [29] showed a high HER-3 expression in $70 \%$ of primary tumors and in $75 \%$ in corresponding CRC lymph node metastases. In previous studies the HER-3 expression had prognostic implications however with ambiguous findings regarding the clinical outcome [29][34][44][45].

In line with several studies of CRC patients [26] [27], we did not find a prognostic benefit for patients with a positive HER-2 status or any correlation between positive HER-2 status and clinico-pathological parameters. As demonstrated in our preliminary studies [23], high HER-2 expression was found mainly in primary tumors in rectal cancer patients $(n=4 ; 18.2 \%)$. The rate of HER-2 positivity in metastases was $8 \%$ analogous to findings from Aprile et al.[28] $(n=50)$ with HER-2 overexpression in $12 \%$ of brain metastases. Furthermore, similarly high levels of concordance were reported for metastases and corresponding primary tumors in CRC patients [28][46]. However, the change from positive HER-2 status in primary tumors to HER-2 negative status in metastases was detected in about $20 \%(n=4)$ of cases. Although this result is limited due to the small amount of assessed primary tumors, this downregulation of HER-2 might be induced by multimodal treatment, as described for breast cancer [47][48] or is an effect of metastatic progression. Therefore, representative slides of the resected tumor rather than metastases may be adequate to evaluate the HER-2 status as a potential target for a specific treatment. Nevertheless, targeting HER-2, HER-3 and other EGFR members simultaneously could have useful applications in metastastic CRC treatment. Although trastuzumab is approved for HER-2 positive metastatic gastric cancer, clinical trials on trastuzumab therapy for (metastatic) CRC are still lacking. In $\mathrm{CRC}$, data reported that a HER-2 overexpression is also involved in response to anti-EGFR therapies. Bertotti et al. [49] identified in vitro the HER-2 overexpression and gene amplification to be a negative determinant in addition to KRAS mutation for response to an anti-EGFR therapy like cetuximab in metastatic CRC. Dual inhibition with anti-EGFR antibodies (cetuximab or pertuzumab) and anti-HER-2 antibody (tyrosine kinase inhibitor lapatinib) led in preclinical studies to a significant regression of the tumor $(-75 \%)$ in comparison to treatment with cetuximab or lapatinib alone. Further analyses and clinical phase II studies are also consistent with these results (DUX study) [50][51] and showed increased survival and response rates and even doubled progressionfree time with dual inhibition versus single antibody therapy.

In cancers with ligand-dependent activation of HER-3, several studies suggest therapeutic potential of anti-HER-3 substances [31][43][52]. Scartozzi et al. [43] showed that HER-3 proved to be a predictive factor for clinical outcome in wild-type KRAS CRC patients treated with cetuximab. Currently, a clinical study evaluates treatment with MM-121 plus cetuximab versus MM121 in combination with cetuximab plus irinotecan in CRC (http://ClinicalTrials.gov: NCT01451632). Another multicenter study is recruiting participants to evaluate RG7116 alone (part A) or in combination with cetuximab (part B) or erlotinib (part C) in patients with metastatic and/or locally advanced malignant HER-3 positive solid tumors (http://ClinicalTrials.gov: NCT01482377). The results remain to be awaited.

In conclusion, HER-2 is detectable in a relevant proportion and HER-3 is highly overexpressed in liver metastases of patients with CRC (HER-2 8\%; HER-3 $75 \%$ ). In patients with overexpression of HER-2 and/ or HER-3 with tumor progression and metastatic spread, targeting these two receptors may hypothetically be beneficial. The HERACLES phase II trial demonstrated with first results that the combination of trastuzumab and lapatinib was effective in standard therapy refractory mCRCs with HER-2 amplification [53]. Prospective clinical trials will be necessary to validate HER-2 and HER-3 as potential targets for precision medicine in the treatment of (metastatic) CRC.

\section{PATIENTS AND METHODS}

This monocentric study included 208 patients (median age: 67.5 years; 71 female (34\%) and 137 male $(66 \%)$ ) with CRLM, treated between April 1982 and January 2013 at the Department of General, Visceral and Pediatric Surgery, University Medical Center Göttingen, Germany. The patients' demographics and clinical characteristics are summarized in Table 1. Patients were eligible if they had $\mathrm{CRC}$ along with the occurrence of either synchronous or 
metachronous liver metastases. Additional screening tests (e. g. CT scan of the abdomen/thorax/brain, bone scintigraphy) were performed to detect signs of extrahepatic tumor manifestations and to verify if CRLM were resectable.

Distant metastases were mainly localized exclusively in the liver ( $n=117 ; 56 \%$ ), followed by metastases detected simultaneously in various organ systems (liver, lungs, peritoneal, bones and/or brain; $n=$ $91,44 \%)$. Most patients presented with lesions in one lobe $(n=105 ; 50 \%)$ or in two lobes of the liver $(n=89 ; 43 \%)$. A total amount of 118 patients (57\%) were diagnosed UICC (Union International Contre le Cancer) stage IV with synchronous metastases (Table 1), while in 90 patients $(43 \%)$ distant metastases occurred within further course of the disease (metachronous metastases). Mostly the primary tumor was located in the rectum $(n=142$; $68 \%$ ). In 66 patients (32\%) it was localized in the colon. Overall, about $98 \%$ of the primary tumors were surgically removed. Only 5 patients $(2 \%)$ had surgery in palliative intention due to an extraorgan extension of CRC and extended findings intraoperatively.

\section{Treatment - surgery and chemotherapy}

In this study, $179(86 \%)$ patients underwent liver surgery including major $(n=102 ; 57 \%)$ or minor $(n=77$; $43 \%$ ) resection of the liver for resectable metastases (Supplementary Table 1). Resectability was assessed by experienced liver surgeons and was determined by the number of metastases, size and account of lesions, the patients' constitution and comorbidity and risk of further damage with fatal outcome (e.g. hepatitis, hepatic failure). Major surgery involved resection of four or more liver segments such as (extended) hemihepatectomy whereas in minor surgery only one or up to three liver segments were resected.

Perioperative combination CTx protocols varied in accordance to patients' tumor genetic profile such as KRAS-status. Patients with a KRAS wild-typ status received the monoclonal antibody cetuximab simultaneously to CTx protocols with doublets ( $n=25 ; 12 \%$; Supplementary Table 1$)$. Bevacizumab, a humanized monoclonal antibody against vascular endothelial growth factor (VEGF), was applied to 24 patients $(12 \%)$. In 6 patients $(3 \%)$, the application of cetuximab additionally to bevacizumab had been performed. One patient received an additional third antibody panitumumab, a humanized monoclonal antibody against epidermal growth factor (EGF).

\section{Immunhistochemistry protocol}

The HER-2 status and HER-3 expression level were determined in 208 formalin-fixed paraffin-embedded tissue samples from hepatic CRC metastases. In addition 22 HER-2 stained resection specimens could also be included in this study, so that 22 matched pairs of CRLM samples and corresponding primary cancer resection specimens were available for further analyses.

HER-2 immunostaining was conducted using a PATHWAY $^{\circledR}$ anti-HER-2/neu (4B5) rabbit monoclonal antibody (Ventana Medical Systems, Mannheim, Germany) on a Ventana BenchMark XT immunostainer (Ventana, Tucson, AZ, US) and visualized by the ultraView Universal DAB Detection Kit (Ventana Medical Systems, Mannheim, Germany). HER-3 expression was determined by using the anti c-erbB-3/HER-3 rabbit monoclonal antibody (clone SP71; Spring Bioscience, Pleasanton, USA). Examples of the immunohistological staining of HER-3 are shown in Figure 2.

For the evaluation of HER-2 and HER-3 we used the testing protocol, which had been developed within the ToGA-trial and is now well established to determine HER-2 expression and amplification in patients with adenocarcinomas of the stomach and the gastroesophageal junction [20][54] and which was used in primary rectal adenocarcinomas before [23].

Scoring criteria included the magnification rule, which allowed an objective and standardized evaluation (Figure 1). The stained tissue samples were classified according to their staining intensity regarding certain magnification in the light microscope. Tumor cells were assessed positive if they had only distinct, regularly striped intercellular membrane staining. The circularity of membrane staining was not a prerequisite for a positive membrane staining. Due to a lack of luminal receptors situated in intestinal glands basolateral or lateral membrane stainings were also taken into account. Cytoplasmic, nuclear or granular staining that may occur among other cases of intestinal metaplasia was not included [25].

Tumor samples were considered IHC $2+$ or IHC $3+$, if at least $10 \%$ of the tumor cells had medium (10x, 20x magnified, IHC 2+) or strong membrane staining at low magnification $(2.5 \mathrm{x}, 5 \mathrm{x}, \mathrm{IHC} 3+)$. No membrane staining was scored IHC 0 and weak membrane staining in at least $10 \%$ of the tumor cells was defined as IHC $1+(40 \mathrm{x}$ magnified).

HER-2 samples scored IHC 2+ were further prepared for detection of gene amplification using Dual-insitu-hybridization (Dual-ISH). In HER-3 stained samples no assessment of gene amplification had been performed (Figure 1).

\section{Dual-ISH protocol}

Dual-ISH was performed in HER-2 cases with equivocal membrane staining (if scored IHC 2+) according to manufactures recommendations by using the Ventana INFORM HER-2 Dual ISH/DNA Probe Cocktail and visualized utilizing two-color chromogenic in situ hybridization (ultraVIEW SISH Detection KIT and ultraVIEW Red ISH DIG Detection Kit, Ventana Medical Systems, Mannheim, Germany). HER-2 gene amplification 
was determined by the count of visualized copies of the HER-2 gene and visualized copies of chromosome 17. Ratios above 2.0 were considered amplified. IHC $3+$ or IHC 2+/Dual-ISH positive (amplified) were classified HER2 positive; IHC 0 , IHC $1+$ or IHC $2+/$ Dual-ISH negative (not amplified) were defined HER-2 negative [23]. IHC and Dual-ISH analyses were performed independently by two different observers (HS and IN).

\section{Statistical analysis}

The association of HER-2 and HER-3 expression levels with other clinico-pathological parameters was assessed using Fisher's exact test. Survival rates were supplied by means of Kaplan-Meier analysis and tested using the Cox proportional hazards model. Overall survival (OS) was defined as interval between surgery of the metastasis and death of any cause and cancer-specific survival (CSS) was defined as time from surgery of the metastasis and cancer related death. The $p$-value was set to $p<0.05$ to be considered statistically significant. Statistical analyses were conducted using $R$ statistical computing environment version 3.1.1 [55]. Survival analysis was performed using the R package survival.

\section{ACKNOWLEDGMENTS}

The authors would like to thank Birgit Jünemann for her excellent technical assistance and for providing outstanding slides for immunohistochemical staining and in-situhybridization. Our thanks are also directed to Merle Heine and Marcus Storch for patient monitoring and data management. We also thank Prof. Dr. G. Vogt, who supported this study.

\section{CONFLICTS OF INTEREST}

This work was supported by the Deutsche Forschungsgemeinschaft (KFO 179-2) and the BMBF consortium MetastaSys (0316173A). Roche Diagnostics provided detection kits for the immunohistochemical staining.

\section{REFERENCES}

1. Siegel R, Naishadham D, Jemal A. Cancer statistics, 2012 CA Cancer J Clin. 2012; 62:10-29.

2. Parkin DM, Whelan SC, Ferlay J, Teppo L, Thomas DB, World Health Organization Cancer Incidence in Five Continents Lyon: The World Health Organization and The International Agency for Research on Cancer 2002; VIII: 1-771.

3. Boyle P, Langman JS. ABC of colorectal cancer: Epidemiology. BMJ. 2000; 321:805-808.

4. Wilmink AB. Overview of the epidemiology of colorectal cancer. Dis Colon Rectum. 1997; 40:483-493.

5. Hong YS, Nam BH, Kim KP, Kim JE, Park SJ, Park YS, Park JO, Kim SY, Kim TY, Kim JH, Ahn JB, Lim SB, $\mathrm{Yu} \mathrm{CS}$, et al. Oxaliplatin, fluorouracil, and leucovorin versus fluorouracil and leucovorin as adjuvant chemotherapy for locally advanced rectal cancer after preoperative chemoradiotherapy (ADORE): an open-label, multicentre, phase 2, randomised controlled trial. Lancet Oncol. 2014; 15:1245-53.

6. Hohenberger W, Weber K, Matzel K, Papadopoulos T, Merkel S. Standardized surgery for colonic cancer: complete mesocolic excision and central ligation-technical notes and outcome. Colorectal Dis. 2009; 11:354-64.

7. Sauer R, Becker H, Hohenberger W, Rödel C, Wittekind C, Fietkau R, Martus P, Tschmelitsch J, Hager E, Hess CF, Karstens JH, Liersch T, Schmidberger H, Raab R. Preoperative versus postoperative chemoradiotherapy for rectal cancer. N Engl J Med. 2004; 351:1731-40.

8. MacFarlane JK, Ryall RD, Heald RJ. Mesorectal excision for rectal cancer. Lancet. 1993; 341:457-60.

9. Homayounfar K, Bleckmann A, Conradi LC, Sprenger T, Lorf T, Niessner M, Sahlmann CO, Meller J, Liersch T, Ghadimi BM. Metastatic recurrence after complete resection of colorectal liver metastases: impact of surgery and chemotherapy on survival. Int J Colorectal Dis. 2013; 28:1009-17.

10. Hackl C, Gerken M, Loss M, Klinkhammer-Schalke M, Piso P, Schlitt HJ. A population-based analysis on the rate and surgical management of colorectal liver metastases in Southern Germany. Int J Colorectal Dis. 2011; 26:1475-1481.

11. Hackl C, Neumann P, Gerken M, Loss M, KlinkhammerSchalke M, Schlitt HJ. Treatment of colorectal liver metastases in Germany: a ten-year population-based analysis of 5772 cases of primary colorectal adenocarcinoma. BMC Cancer. 2014; 14:810.

12. Kato $\mathrm{T}$, Yasui $\mathrm{K}$, Hirai $\mathrm{T}$, Kanemitsu Y, Mori $\mathrm{T}$, Sugihara K, Mochizuki H, Yamamoto J. Therapeutic results for hepatic metastasis of colorectal cancer with special reference to effectiveness of hepatectomy: analysis of prognostic factors for 763 cases recorded at 18 institutions. Dis Colon Rectum. 2003; 46:S22-31.

13. Abdalla EK, Vauthey JN, Ellis LM, Ellis V, Pollock R, Broglio KR, Hess K, Curley SA. Recurrence and outcomes following hepatic resection, radiofrequency ablation, and combined resection/ablation for colorectal liver metastases. Ann Surg. 2004; 239:818-827.

14. Seymour MT, Maughan TS, Ledermann JA, Topham C, James R, Gwyther SJ, Smith DB, Shepherd S, Maraveyas A, Ferry DR, Meade AM, Thompson L, Griffiths GO, et al. Different strategies of sequential and combination chemotherapy for patients with poor prognosis advanced colorectal cancer (MRC FOCUS): a randomised controlled trial. Lancet. 2007; 370:143-52.

15. Koopman M, Antonini NF, Douma J, Wals J, Honkoop AH, Erdkamp FL, de Jong RS, Rodenburg CJ, Vreugdenhil G, Loosveld OJ, van Bochove A, Sinnige HA, Creemers GJ, et al. Sequential versus combination chemotherapy with capecitabine, irinotecan, and oxaliplatin in advanced 
colorectal cancer (CAIRO): a phase III randomised controlled trial. Lancet. 2007; 370:135-42.

16. Folprecht G, Gruenberger $\mathrm{T}$, Bechstein W, Raab HR, Weitz J, Lordick F, Hartmann JT, Stoehlmacher-Williams J, Lang H, Trarbach T, Liersch T, Ockert D, Jaeger D, et al. Survival of patients with initially unresectable colorectal liver metastases treated with FOLFOX/cetuximab or FOLFIRI/cetuximab in a multidisciplinary concept (CELIM study). Ann Oncol. 2014; 25:1018-25.

17. Ye LC, Liu TS, Ren L, Wei Y, Zhu DX, Zai SY, Ye QH, $\mathrm{Yu}$ Y, Xu B, Qin XY, Xu J. Randomized controlled trial of cetuximab plus chemotherapy for patients with KRAS wildtype unresectable colorectal liver-limited metastases. J Clin Oncol. 2013; 31:1931-8.

18. Piccart-Gebhart MJ, Procter M, Leyland-Jones B, Goldhirsch A, Untch M, Smith I, Gianni L, Baselga J, Bell R, Jackisch C, Cameron D, Dowsett M, Barrios CH, et al. Trastuzumab after adjuvant chemotherapy in HER2-positive breast cancer. N Engl J Med. 2005; 353:1659-72.

19. Romond EH, Perez EA, Bryant J, Suman VJ, Geyer CE Jr, Davidson NE, Tan-Chiu E, Martino S, Paik S, Kaufman PA, Swain SM, Pisansky TM, Fehrenbacher L, et al. Trastuzumab plus adjuvant chemotherapy for operable HER2-positive breast cancer. N Engl J Med. 2005; 353:1673-84.

20. Bang YJ, Van Cutsem E, Feyereislova A, Chung HC, Shen L, Sawaki A, Lordick F, Ohtsu A, Omuro Y, Satoh T, Aprile G, Kulikov E, Hill J, et al. Trastuzumab in combination with chemotherapy versus chemotherapy alone for treatment of HER2-positive advanced gastric or gastro-oesophageal junction cancer (ToGA): a phase 3, open-label, randomised controlled trial. Lancet. 2010; 376:687-97.

21. Yoon HH, Shi Q, Sukov WR, Wiktor AE, Khan M, Sattler CA, Grothey A, Wu TT, Diasio RB, Jenkins RB, Sinicrope FA. Association of HER2/ErbB2 expression and gene amplification with pathologic features and prognosis in esophageal adenocarcinomas. Clin Cancer Res. 2012; 18:546-54.

22. Komoto M, Nakata B, Amano R, Yamada N, Yashiro M, Ohira M, Wakasa K, Hirakawa K. HER2 overexpression correlates with survival after curative resection of pancreatic cancer. Cancer Sci. 2009; 100:1243-7.

23. Conradi LC, Styczen H, Sprenger T, Wolff HA, Rödel C, Nietert M, Homayounfar K, Gaedcke J, Kitz J, Talaulicar R, Becker H, Ghadimi M, Middel P, et al. Frequency of HER-2 positivity in rectal cancer and prognosis. Am J Surg Pathol. 2013; 37:522-31.

24. Van Cutsem E, Bang YJ, Feng-Yi F, Xu JM, Lee KW, Jiao SC, Chong JL, López-Sanchez RI, Price T, Gladkov O, Stoss $\mathrm{O}$, Hill J, Ng V, et al. HER2 screening data from ToGA: targeting HER2 in gastric and gastroesophageal junction cancer. Gastric Cancer. 2014; [Epub ahead of print].

25. Hofmann M, Stoss O, Shi D, Büttner R, van de Vijver M, Kim W, Ochiai A, Rüschoff J, Henkel T. Assessment of a HER2 scoring system for gastric cancer: results from a validation study. Histopathology. 2008; 52:797-805.

26. Wu SW, Ma CC, Yang Y. The prognostic value of HER-2/ neu overexpression in colorectal cancer: evidence from 16 studies. Tumour Biol. 2014; 35:10799-804.

27. Han J, Meng QY, Liu X, Xi QL, Zhuang QL, Wu GH. Lack of Effects of HER-2/neu on Prognosis in Colorectal Cancer: a Meta-analysis. Asian Pac J Cancer Prev. 2014; 15:5551-6.

28. Aprile G, De Maglio G, Menis J, Casagrande M, Tuniz F, Pisa EF, Fontanella C, Skrap M, Beltrami AC, Fasola G, Pizzolitto S. HER-2 Expression in Brain Metastases from Colorectal Cancer and Corresponding Primary Tumors: A Case Cohort Series. Int J Mol Sci. 2013; 14:2370-87.

29. Lédel F, Hallström M, Ragnhammar P, Öhrling K, Edler D. HER3 expression in patients with primary colorectal cancer and corresponding lymph node metastases related to clinical outcome. Eur J Cancer. 2014; 50:656-62.

30. Ho-Pun-Cheung A, Assenat E, Bascoul-Mollevi C, Bibeau F, Boissière-Michot F, Cellier D, Azria D, Rouanet P, Senesse P, Ychou M, Lopez-Crapez E. EGFR and HER3 mRNA expression levels predict distant metastases in locally advanced rectal cancer. Int J Cancer. 2011; 128:2938-46.

31. Mirschberger C, Schiller CB, Schraml M, Dimoudis N, Friess T, Gerdes CA, Reiff U, Lifke V, Hoelzlwimmer G, Kolm I, Hopfner KP, Niederfellner G, Bossenmaier B. RG7116, a therapeutic antibody that binds the inactive HER3 receptor and is optimized for immune effector activation. Cancer Res. 2013; 73:5183-94.

32. Lee JC, Wang ST, Chow NH, Yang HB. Investigation of the prognostic value of coexpressed erbB family members for the survival of colorectal cancer patients after curative surgery. Eur J Cancer. 2002; 38:1065-71.

33. Alimandi M, Romano A, Curia MC, Muraro R, Fedi P, Aaronson SA, Di Fiore PP, Kraus MH. Cooperative signaling of ErbB3 and ErbB2 in neoplastic transformation and human mammary carcinomas. Oncogene. 1995; 10:1813-21.

34. Beji A, Horst D, Engel J, Kirchner T, Ullrich A. Toward the Prognostic Significance and Therapeutic Potential of HER3 Receptor Tyrosine Kinase in Human Colon Cancer. Clin Cancer Res. 2012; 18:956-68.

35. Wei Q, Shui Y, Zheng S, Wester K, Nordgren H, Nygren P, Glimelius B, Carlsson J. EGFR, HER2 and HER3 expression in primary colorectal carcinomas and corresponding metastases: Implications for targeted radionuclide therapy. Oncol Rep. 2011; 25:3-11.

36. Tolaney S. New HER2-Positive Targeting Agents in Clinical Practice. Curr Oncol Rep. 2014; 16:359.

37. Welslau M, Dieras V, Sohn JH, Hurvitz SA, Lalla D, Fang L, Althaus B, Guardino E, Miles D. Patient-reported outcomes from EMILIA, a randomized phase 3 study of trastuzumab emtansine (T-DM1) versus capecitabine and lapatinib in human epidermal growth factor receptor 
2-positive locally advanced or metastatic breast cancer. Cancer. 2014; 120:642-651.

38. Alba E, Albanell J, de la Haba J, Barnadas A, Calvo L, Sánchez-Rovira $\mathrm{P}$, Ramos $\mathrm{M}$, Rojo F, Burgués $\mathrm{O}$, Carrasco E, Caballero R, Porras I, Tibau A, et al. Trastuzumab or lapatinib with standard chemotherapy for HER2-positive breast cancer: results from the GEICAM/2006-14 trial. Br J Cancer. 2014; 110:1139-47.

39. Eskens FA, Mom CH, Planting AS, Gietema JA, Amelsberg A, Huisman $\mathrm{H}$, van Doorn L, Burger $\mathrm{H}$, Stopfer P, Verweij J, de Vries EG. A phase I dose escalation study of BIBW 2992, an irreversible dual inhibitor of epidermal growth factor receptor 1 (EGFR) and 2 (HER2) tyrosine kinase in a 2-week on, 2-week off schedule in patients with advanced solid tumours. Br J Cancer. 2008; 98:80-5.

40. LoRusso P, Jänne PA, Oliveira M, Rizvi N, Malburg L, Keedy V, Yee L, Copigneaux C, Hettmann T, Wu CY, Ang A, Halim AB, Beckman RA, et al. Phase I study of U3-1287, a fully human anti-HER3 monoclonal antibody, in patients with advanced solid tumors. Clin Cancer Res. 2013; 19:3078-87.

41. Ljuslinder I, Malmer B, Isaksson-Mettävainio M, Oberg A, Henriksson R, Stenling R, Palmqvist R. ErbB 1-4 expression alterations in primary colorectal cancers and their corresponding metastases. Anticancer Res. 2009; 29:1489-94.

42. Kountourakis P, Pavlakis K, Psyrri A, Rontogianni D, Xiros N, Patsouris E, Pectasides D, Economopoulos T. Prognostic significance of HER3 and HER4 protein expression in colorectal adenocarcinomas. BMC Cancer. 2006; 6:46.

43. Scartozzi M, Mandolesi A, Giampieri R, Bittoni A, Pierantoni C, Zaniboni A, Galizia E, Giustini L, Silva RR, Bisonni R, Berardi R, Biscotti T, Biagetti S, et al. The role of HER-3 expression in the prediction of clinical outcome for advanced colorectal cancer patients receiving irinotecan and cetuximab. Oncologist. 2011; 16:53-60.

44. Baiocchi G, Lopes A, Coudry RA, Rossi BM, Soares FA, Aguiar S, Guimarães GC, Ferreira FO, Nakagawa WT. ErbB family immunohistochemical expression in colorectal cancer patients with higher risk of recurrence after radical surgery. Int J Colorectal Dis. 2009; 24:1059-68.

45. Ocana A, Vera-Badillo F, Seruga B, et al. HER3 overexpression and survival in solid tumors: a meta-analysis. J Natl Cancer Inst. 2013; 105:266-73.

46. Half E, Broaddus R, Danenberg KD, Danenberg PV, Ayers GD, Sinicrope FA. HER-2 receptor expression, localization, and activation in colorectal cancer cell lines and human tumors. Int J Cancer. 2004; 108:540-8.

47. van de Ven S, Smit VT, Dekker TJ, Nortier JW, Kroep JR. Discordances in ER, PR, and HER2 receptors after neoadjuvant chemotherapy in breast cancer. Cancer Treat Rev. 2011; 37:422-30.

48. Skálová H, Dundr P, Povýšil C, Velenská Z, Petruželka L, Tvrdík D. Study of the effect of neoadjuvant chemotherapy on the status of Her2/neu. Folia Biol (Praha). 2011; 57:191-9.

49. Bertotti A, Migliardi G, Galimi F, Sassi F, Torti D, Isella C, Corà D, Di Nicolantonio F, Buscarino M, Petti C, Ribero D, Russolillo N, Muratore A, et al. A Molecularly Annotated Platform of Patient-Derived Xenografts ("Xenopatients:") Identifies HER2 as an Effective Therapeutic Target in Cetuximab-Resistant Colorectal Cancer. Cancer Discovery. $2011 ; 1: 508-23$.

50. Weickhardt AJ, Price TJ, Chong G, Gebski V, Pavlakis N, Johns TG, Azad A, Skrinos E, Fluck K, Dobrovic A, Salemi R, Scott AM, Mariadason JM, Tebbutt NC. Dual targeting of the epidermal growth factor receptor using the combination of cetuximab and erlotinib: preclinical evaluation and results of the phase II DUX study in chemotherapyrefractory, advanced colorectal cancer. J Clin Oncol. 2012; 30:1505-12.

51. Yonesaka K, Zejnullahu K, Okamoto I, Satoh T, Cappuzzo F, Souglakos J, Ercan D, Rogers A, Roncalli M, Takeda M, Fujisaka Y, Philips J, Shimizu T, et al. Activation of ERBB2 signaling causes resistance to the EGFR-directed therapeutic antibody cetuximab. Sci Transl Med. 2011; 3:99ra86.

52. Schoeberl B, Pace EA, Fitzgerald JB, Harms BD, Xu L, Nie L, Linggi B, Kalra A, Paragas V, Bukhalid R, Grantcharova V, Kohli N, West KA, et al. Therapeutically Targeting ErbB3: A Key Node in Ligand-Induced Activation of the ErbB Receptor-PI3K Axis. Sci Signal. 2009; 2:ra31.

53. Siena S, Sartore-Bianchi A, Trusolino L, Martino C, Bencardino K, Lonardi S, Leone F, Zagonel V, Bertotti A, Valtorta E, Siravegna G, Amatu A, Vanzulli A, Regge D, Ghezzi S, Ciardiello F, Veronese S, Comoglio PM, Bardelli A, Marsoni S. Therapeutic dual inhibition of HER2 pathway for metastatic colorectal cancer (mCRC): The HERACLES trial. J Clin Oncol 33, 2015; (suppl 3, abstr 565).

54. Ruschoff J, Dietel M, Baretton G, Arbogast S, Walch A, Monges G, Chenard MP, Penault-Llorca F, Nagelmeier I, Schlake W, Höfler H, Kreipe HH. HER2 diagnostics in gastric cancer-guideline validation and development of standardized immunohistochemical testing. Virchows Arch. 2010; 457:299-307.

55. Team RDC. R: Language and Environment for Statistical Computing. http://www.r-project.org/2011. Accessed: 01.11.20112011. 